\title{
Decolonizing a food system: Freedom Farmers' Market as a place for resistance and analysis
}

COMMENTARY ON RACE AND ETHNICITY IN FOOD SYSTEMS

\author{
Gail P. Myers * \\ Farms to Grow, Inc.
}

Submitted June 22, 2015 / Published online September 11, 2015

Citation: Myers, G. P. (2015). Decolonizing a food system: Freedom Farmers' Market as a place for resistance and analysis. Journal of Agriculture, Food Systems, and Community

Development, 5(4), 149-152. http://dx.doi.org/10.5304/jafscd.2015.054.025

Copyright (C) 2015 by New Leaf Associates, Inc.

\begin{abstract}
Oakland's Freedom Farmers' Market is more than a venue for food exchange; it is a gathering place for Black cultural expression and economics. More often than not, Black farmers are shut out and even pushed out of mainstream farmers markets. However, fresh food and Black farmers are celebrated at the Freedom Farmers' Market each week. This commentary discusses the critical ways in which this market represents a social discourse about decolonizing our food system. Embedded within this place analysis is also, necessarily, a critique of the dominant places people currently
\end{abstract}

* Dr. Gail P. Myers, Co-Founder, Farms to Grow, Inc.; P. O. Box 10504; Oakland, California 94610 USA; +1-415-3740608; gpmyers@,farmstogrow.com have available for food. The Freedom Farmers' Market has become a model for disenfranchised peoples to take control of their own food system.

\section{Keywords}

Black farmers, decolonizing food, farmers markets, Black economics, Black farmers markets

Look closely at the land. Imagine vast fields of okra, peas, turnip greens, watermelon, collards and squash weaving themselves together into a forest of bright colors and amazing shapes. Can you see those crops in vast rural fields on the Motherland where for thousands of years the ancestors toiled with bare feet and bared hands, bending backs into ground, planting not only their hopes but the dreams of their children to come? Can you see those same crops 
traveling through the diaspora, those same ancestors, backs bent further, their hopes and dreams now chained, beaten, but still growing, surviving in the richness of legacies encompassed in their foods? Through all the hardships life would bring, the ancestors will continue to plant the crops that feed their children. Through it all these crops will be the salve they have to heal the wounds and nourish the future, a future they continue to grow with their own hands, a future they are determined their children will see: A free future. Our future.

$\mathrm{E}$ very Saturday in Oakland, California, Black food liberation takes place in the form of the Freedom Farmers' Market (http://www.farmsto grow.com) - a culturally specific, historically rooted market experience that is bringing Black residents together with Black farmers in a setting reminiscent of an African marketplace. This marketplace was named to honor the work of freedom fighter Fannie Lou Hamer. In rural Mississippi, Fannie Lou Hamer started the farm cooperative called the Freedom Farms. That this freedom movement continues today in Oakland is appropriate. Oakland was home to the Black Panther Party, whose 10-point plan aimed for everybody to have enough food, housing, health, and education to meet their needs. It is the city where the Black Panthers began their Free Children's Breakfast Program, which caused FBI Director J. Edgar Hoover to call the group the "the greatest threat to the internal security of the country." Grits, not guns, were what worried Hoover. By serving children breakfast, the FBI director said, the Black Panthers were "infiltrating the black community." The Freedom Farmers" Market builds on that breakfast program freedom movement and on an earlier Black farmers' market started in the late 1990s by David Roach and his organization, Mo' Better Foods.

Managed by Farms to Grow, Inc., a Black-run organization, the Freedom Farmers' Market is a place for farmers, vendors, educators, and others with resources to address the current power dynamics between the marginalized communities of people and the dominant class structure. Farms to Grow's approach is unlike the large farmers market associations. Freedom Farmers' Market's primary goals extend beyond making money to focus on community empowerment, farmer outreach, and cultural celebration and preservation. What we have learned is that we should not seek to become a market that is interested only in profits because such an entity is not holistic in its approach and cannot serve more than a small number of individuals. The Freedom Farmers' Market strives to involve the community as a whole in order to ensure that transformation can take place on a scale greater than the individual. We remember the lessons of a past time when people had some understanding of the fact that individuals need more than the financial success that is represented in money. They also need to feed their minds and spirits, as well as their bodies. The spiritual, psychological, and cultural resiliency features that are built into the Freedom Farmers' Market are incalculable.

Cooperation and cultural celebration are two of the principles at the heart of the Freedom Farmers' Market. A farmers market like this, with a focus on the Black experience, can do more than build a local food system: it can create a cooperative environment that has the power to transform the whole community by reintroducing sustainable views of nature through recollections of our folkways and old ways that mattered. Such a farmers market can facilitate a communal perspective and cultural resiliency.

Venues for commerce where Black dollars are spent purchasing food from Black farmers and vendors can be transformative. Without such intentional venues, which themselves provide for a type of analysis of race and privilege, decolonization of a food system may not occur. The Freedom Farmers' Market represents a point of critical analysis as well as a place for the decolonization of the current supply-chain food system. In the process of organizing an all-Black farmers' market, we inadvertently began to take our power back in the local food system. We reached out to, recruited, trained, and eventually brought Black farmers, food businesses, and culturally relevant health information into a setting that necessarily is itself a social discourse about decolonizing our food systems. Embedded within this place analysis is also necessarily a critique of the dominant places people 
currently seek groceries and community enrichment.

We sought to shift the discourse in order to drive change from within marginalized food communities to continue to reduce their dependence upon dominant food access points. Commerce can be mixed with cultural food access, and people can be released from the shackles of a colonized supply-chain food system. The Freedom Farmers' Market, itself claimed from the decolonized approaches of freedom fighters, situates its dominant food story within the oppressed stakeholders. The reconstruction of traditional foodways and decolonization of food systems require a liberator space for the redevelopment of traditional identities and more expansive farming narratives where land, people, and food are one.

Unfortunately, the USDA's agricultural policies have always been deeply rooted in a supply-chain philosophy, which allows for greater manipulation of the food supply and pricing by Wall Street, and also creates food gaps, food deserts, land loss, and inequalities in the various layers of the food system. The Freedom Farmers' Market took the opportunity to fill in these gaps of the broken food chain, which ignores Black farmers and slights Black food businesses. We have created a venue for our farmers to bring forth the fruits of their labors that carry the legacies of our food past. The approach brings with it much more than fresh food. When traditional people are able to reclaim their food histories, they may be more likely to overcome the decolonization wreckage pervasive in urban centers. The Freedom Farmers' Market challenges the historical assumptions that there are no Black farmers or that Black food economics do not exist. It is important that Black communities know that Black farmers are still keeping the traditions, despite a mostly hostile atmosphere where White supremacy has haphazardly dismantled Black farmer developments, Black towns, and business districts, and has removed swaths of people from their land.

Imperialism's praxis has left a remarkable trail of people disconnected from their sustainable traditions, with whole histories interrupted by the convenience of Western enlightenment and the accompanying world belief systems. The Freedom
Farmers' Market addresses these effects. It is the resiliency praxis that liberates, decolonizes food spaces, and connects people back to sacred times and spaces. Agroecological environments included sacred spaces where the elders went to pray and forage for herbs and food-food they planted by the signs of the moon, by the rotation process, with the three sisters, all in prayer. We used to know the accompanying herbs to serve with our foods to help it digest better and absorb some of the fat that was inherent in the dish. Although this knowledge lost to many individuals, it has not been lost to our culture because it survives with the farmers and herbalists who still have access to the land. Bringing these farmers and herbalists back together with our urban residents brings this knowledge back to the greater community.

We began the Freedom Farmers' Market because we needed to honor our Black farmers; we needed a safe place to reclaim our legacy around food and community; and we wanted to opt out of the dominant supply-chain food system. Through the market we have demonstrated that creating community around food in the quest for freedom is grounding and can serve as a bridge between the years of the past to the hopes of today and beyond. The Freedom Farmers' Market can and has become a model for disenfranchised peoples to take control of their own food system.

The creation of a culturally specific farmers market community as a revolutionary praxis and a place of resiliency shifts focus from the individualist notions of liberty so deeply rooted in American culture to one on the cooperative and communal characteristics of freedom. In mainstream Western spaces such as predominantly White farmers markets, Black folks can find only slight resemblances of themselves culturally. We find few if any cultural markers of significance. The Freedom Farmers' Market (re)presents an African-based perspective, while defining itself as a place of resilience reclaiming local wisdom and foodways. Nonetheless, it is also a safe and profitable place. Black people who come say it is like walking through an oasis of safety. White people who come through pay respects to Black culture and appreciate the diversity. We have created a hub of Black culture while providing critical access to healthy, fresh 
food in places where this has not existed.

We need spaces that represent the resiliency to resist that which cannot be exacted. Providing people with a choice as to where they spend their food dollars is decolonizing the food system. The availability of fresh, culturally relevant produce is decolonizing people's diets. We can look at the Freedom Farmers' Market as a model and a guide. Starting with really small, concrete steps we have reconnected Black growers with Black consumers, and as a result we are reconnecting the people with the culture that is inherent in our legacy foods.

We also talk about how we can recover some of the ancestral knowledge that people hold in their immediate families. Sharing in recipe stories and other food stories provides a positive occasion for Black people to remember fondly and proudly in a safe and supportive environment. Pea-shelling contests, watermelon-eating contests, blues, gospel, and jazz music, dancing, and poetry are all cultural expressions and celebrations that connect us to historical places and honor Black culture and community. Decolonizing our diet also means honoring our ancestors and the earth, and fostering sustainability. The African natural world view calls for us to be accountable not only to the community, but also to the forest, water, soils, and livestock. This world view has been passed down through generations of Black farmers, and their presence in the community models critical lessons for those who have lost touch with the land. The Freedom Farmers' Market in Oakland has brought various stakeholders together and is implementing food justice by practicing communal food autonomy. Reclaiming our food spaces in the way that the Freedom Farmers' Market has resists the food colonization that has left us in a desert. When we name our liberation spaces within our own community struggle for freedom, we bring back our cultural roots of self-sufficiency. Choosing to decolonize a food system is a quest to be free, truly freed. This liberating act of maintaining a farmers market around food freedom is at the heart of decolonization. 